\title{
Flow and scour around vertical submerged structures
}

\author{
KRISHNA PADA BAURI and ARINDAM SARKAR* \\ School of Infrastructure, Indian Institute of Technology Bhubaneswar, Bhubaneswar 751013, India \\ e-mail: kb13@iitbbs.ac.in; asarkar@iitbbs.ac.in
}

MS received 10 June 2015; revised 15 December 2015; accepted 16 April 2016

\begin{abstract}
The safety of the foundations of submerged hydraulic structures due to excessive local scour is threatened by the erosive action of the waves and currents passing around these structures. Fish and aquatic habitat is seriously affected due to the modification of the flow field caused by these submerged structures. Hence, the problems of flow characteristics and erosion around submerged structures were investigated by various researchers. A comprehensive discussion of the investigations on flow characteristics and local scour due to steady currents and waves around vertical submerged structures are presented, which comprises scour process, dimensional analysis, parameters influencing scour, temporal evolution of scour, flow field, flow visualization techniques, variation of bed shear stress, scour depth determination formulas and scour countermeasures. Although past investigations establish the effect of various parameters on scour around vertical submerged structures for live and clear water condition, yet further studies are required to analyze the scour around group of submerged structures for various bed sediments, understand the flow physics around the group and upscale the model results for the prototype.
\end{abstract}

Keywords. Scour; erosion; sediment transport; submerged structure.

\section{Introduction}

Scour is a process caused mainly by the flow of streams and rivers on erodible sediment beds. Foundations of submerged hydraulic structures may be undermined due to excessive local scour. Local scour around these submerged structures are considered in designing the foundation of these structures.

Hence, over the years, considerable studies were conducted to study the flow and local scour around vertical submerged structures. This paper attempts to discuss the past investigations on hydraulics and local scour around vertical submerged structures. It includes scour process, parameters influencing scour, temporal evolution of scour, flow field, flow visualization techniques, variation of bed shear stress, scour depth estimation formulas and scour countermeasures.

\section{Scour around vertical submerged structures}

\subsection{Scour process}

Sediment particles around submerged structures are on the threshold to move due to the generation of higher bed shear stress in comparison to the critical bed shear stress for the

*For correspondence movement of these particles. Scour is caused by the formation of horseshoe vortex close to the bed, which forms as the flow gets modified around vertical submerged structures as shown in figure 1 . The horseshoe vortex forms due to the negative pressure gradient at the upstream of the structures. The adverse pressure gradient creates downflow at the upstream of the structure, which reaches the bottom of the erodible bed and takes the form of horseshoe vortex. The mode and the way sediment is transported, lays the basis for the categorization of the scour process into clear-water and live bed scour. During clear water scour, although the stream doesn't carry any sediment but being only picked up from the scour hole, whereas, for live bed scour, simultaneously sediment is fed and removed by the stream within the hole. The pier Reynolds number is an important variable, which affects the intensity of the generated horseshoe vortices. Various researchers have investigated the flow and scour around different vertical submerged structures. Hannah [1] carried out pioneering investigations on the scour mechanism around complex pile groups due to three-dimensional flows around the structures. The various regular grids of the structures were investigated and the temporal variation of scour and deposition pattern around these structures was measured. Albers [2] experimentally studied the flow around three obstacle clusters and investigated the effect of depth of flow and spacing between the obstacles on the flow. It has been found that the cluster behaves like a single obstacle for center to center spacing between the 


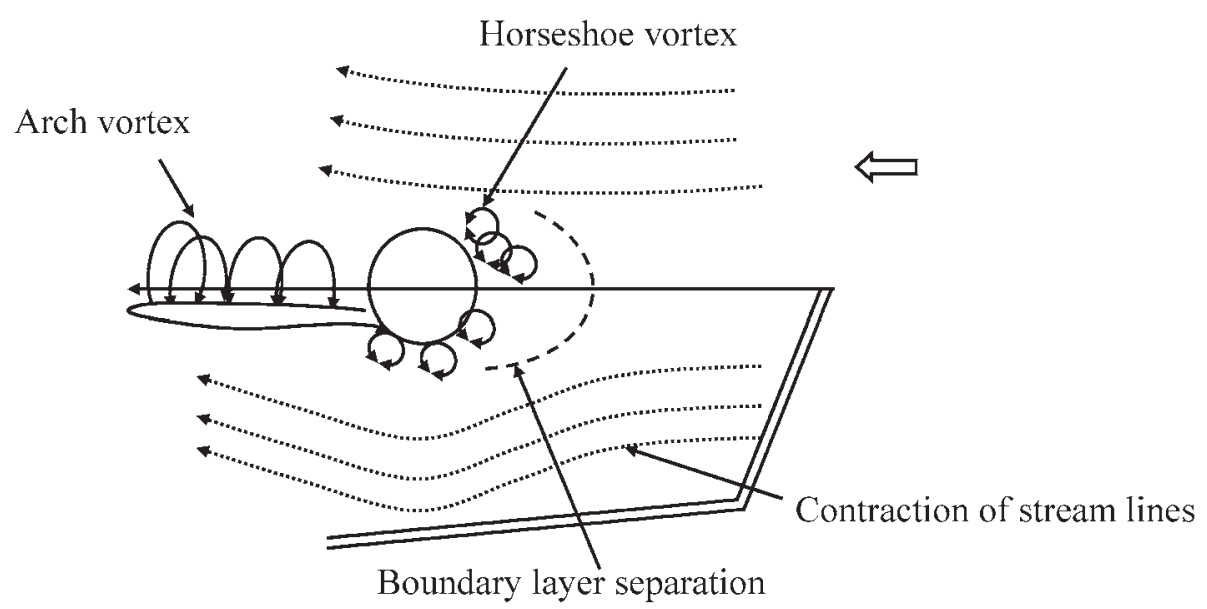

Figure 1. Definition sketch of flow around bottom-mounted sphere, Shamloo et al [6].

clusters as 1.1 times obstacle diameter or less. It has also been observed that for this spacing, single horseshoe vortex is formed, which helps in the development of the bed around the cluster. Also the scour process around group of hemispherical structures for various submergence ratios was reported. Tang and Chang [3] did the experimental and numerical investigation on vortex formation due to wave around rectangular submerged obstacles and showed that scour occurs due to primary and secondary vortex. The degeneration of primary vortex depends on time and the size and intensity of the primary vortex influence the development of secondary vortex. They found that the temporal variation of the vortex shedding and changes in the flow patterns matched well with numerical results. Voropayev et al [4] experimentally investigated the sand ripples that were formed due to movement of wave over erodible beds. Scour and burial around cobbles in oscillatory flow were also investigated. They observed that the scour process occurred mainly due to the modification of the flow field around the cobbles, whereas high local fluid velocity was formed around the structures leading to the burial phenomenon. Depending on the location, they also distinguished the scour process in four different ways; around, side, bottom and near the cobbles. McNinch et al [5] investigated the scour process at near shore shallow water around completely submerged wreck sites and concluded that scour process remains active during severe storm events. Shamloo et al [6] determined the equilibrium clear water scour around hemispheres and discussed the scour process and pattern around the structures. It was reported that scour occurs due to high velocity and strong down flow around the spherical structure. The sediments are eroded, moved and deposited on the downstream side of the spherical body. Figure 1 shows the typical pattern of scour, erosion and deposition around the spherical structure for different regimes in the river. They also observed that scour initiates at the side of spherical structure and gradually the scour hole moves in the upstream of the structure.
Voropayev et al [7] experimentally investigated the scour and burial around the short cylinder due to progressive shoaling waves and reported four scour regimes (i.e., no scour, initial scour, developed scour and intermittent burial). It has been observed that scour does not get initiated till the velocity of water reaches the critical value, initial scour occurs due to nonlinearity of the waves around the onshore and offshore sides of the cylinder, but rate of initial scour is less on the offshore sides of the cylinder. Scour occurs for larger values of KC number, Shields parameter and small height of sand ripples. Periodic burial occurs for sand ripples height larger than the diameter of the cylinder. Myrhaug and Rue $[8,9]$ analyzed the scour process below pipelines as well as around vertical piles due to combined random waves and currents. It was assumed that the free surface elevation was stationary and each wave was treated individually to calculate the scour depth due to random waves. Myrhaug and Rue [9] studied the scour around group of vertical piles due to waves for live bed condition using stochastic approach and experimental data of Sumer and Fredsøe [10]. It has been found that the value of the average scour depth depends on the wave characteristics. Truelsen et al [11] experimentally investigated scour around spherical bodies due to steady current and waves on an erodible seabed. Scour occurs mainly due to horseshoe vortex and a strong downward flow, which scours and pushes the scoured material behind the spherical body (figure 2). A weak upstream vortex and adverse pressure gradient is formed at the upstream of the spherical body whereas an arch horseshoe vortex is formed at downstream of the spherical body due to reattachment from bed as shown in figure 2 . They found that the recirculation occurs in the wake of the spherical body and contraction of streamlines is developed at sides of the spherical body. They also found that the ratio of scour depth to the spherical diameter is always smaller in waves than in steady current. On the other hand, Catano-Lopera and Garcia $[12,13]$ experimentally studied scour process around 


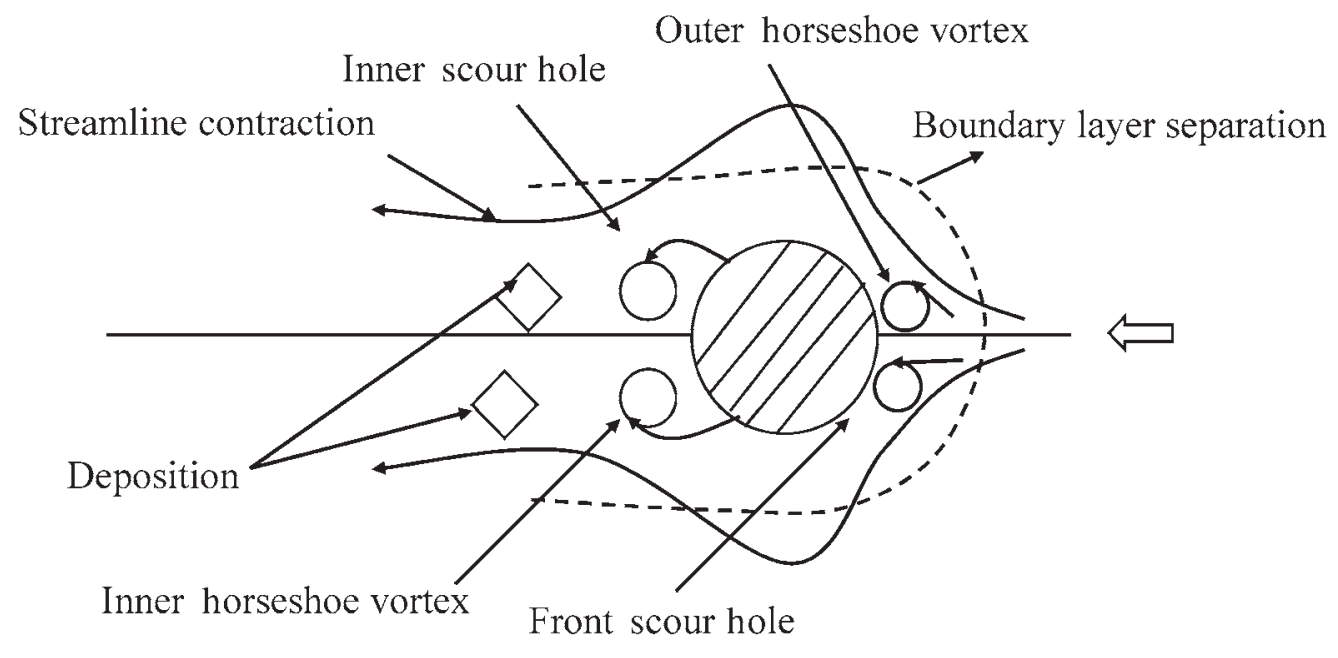

Figure 2. Typical pattern of erosion and deposition around the spherical structure, Truelsen et al [11].

cylinder due to combined waves and currents. Dey et al [14] experimentally studied the prediction of scour around vertical circular piles due to steady current and waves for clear water and live bed scour condition. It has been observed that the down flow and horseshoe vortex are the main scouring agents. Quinn [15] studied the local scour around shipwreck at the bottom of the seafloor. The modification of the flow field depends on the horseshoe vortex at the front and lee vortex at the downstream of the structure. Erosion due to both steady and oscillatory flows is considered pertinent to a shipwreck site. Hatton et al [16] numerically studied scour around a short cylinder in wave and steady flow conditions. They observed scour and intermittent burial for all flow conditions. It has been found that scour is maximum at upstream of cylinder when average flow is greater than $10 \mathrm{~cm} / \mathrm{s}$. They also concluded that with increase in velocity, scour depth increases whereas deposition decreases around the cylinder. Dey et al [17] experimentally observed scour around circular cylinders on erodible and plane bed. The scour depth was observed to increase with decrease of submergence ratio. However, they only considered the scour depth around submerged cylinder under clear water condition and compared with scour depth around partially submerged cylinder of same diameter, flow and sediment bed condition. The scour hole decreases with decrease in horseshoe vortex and scour hole is smaller in case of submerged cylinder compared to partially submerged cylinder. Sadeque et al [18] experimentally investigated the hydraulics around fully and partially submerged cylindrical structures. The horse-shoe vortex developed closer to the submerged cylinders in comparison to the free surface penetrating cylinders. It was also pointed out that the submerged cylinders suppress the alternate vortex shedding and rather generate strong threedimensional downstream wakes, which result in very high bed shear stress at the lateral face of the submerged cylinder. They also simulated the erosion and deposition of bed sediments for both coarse and fine sands. Myrhaug et al
[19] also analyzed the scour process below pipelines as well as around vertical piles due to combined random waves and currents. It was assumed that the free surface elevation was stationary and each wave was treated individually to calculate the scour depth due to random waves. However, Myrhaug et al [19] also conducted experiments on scour around vertical piles due to waves under live bed condition. Ataie-Ashtiani et al [20] experimentally studied clear-water local scour around submerged compound piers. Various shapes and sizes of the piers were considered. The scour process reaches equilibrium condition for the cases when scour hole reaches the pile cap. The scour hole development process varies also with the pile configuration. Euler and Herget [21] experimentally studied the local scour and deposition around various structures under clear water condition and discussed the scour process due to horseshoe vortex over two different bed conditions (i.e., erodible and flat rigid bed). The negative pressure gradient at the upstream of the submerged structure helps in the formation of a horseshoe shaped vortex close to the bed. Consequently, the shear stress at the bed gets amplified and exceeds the critical bed shear stress for the bed material resulting in the scour process. Steady and subcritical flow conditions were considered during the experiments and non- cohesive sediments were used as the bed material.

\subsection{Dimensional analysis}

Using physical and logical reasoning; and applying Buckingham $\pi$-theorem, investigators represented the scour depth in terms of different parameters related with the scour process in non-dimensional forms. Catano-Lopera and Garcia [22] experimentally studied the scour hole characteristics, burial of cylinders and effect of angle of flow on the scour and burial around cylinders. They observed that the width and length of evolved bed and burial depth depend on Shields parameter and KC number around the 
cylinder. Further they expressed depth of scour in terms of the following parameters:

$$
D_{\mathrm{s}}=f\left(d, h, \rho_{\mathrm{c}}, \varepsilon, D_{\mathrm{m}}, \rho_{\mathrm{s}}, \sigma_{\mathrm{gd}}, t, U_{\mathrm{w}}, U_{\text {mean }}, T_{\mathrm{w}}, v, g, \alpha_{\mathrm{i}}, B_{\mathrm{d} 0}\right)
$$

where $D_{\mathrm{s}}=$ maximum scour at any time $t, d=$ diameter of pile, $h=$ pier height, $\rho_{\mathrm{c}}=$ density of cylinder, $\varepsilon=$ surface roughness of cylinder, $D_{\mathrm{m}}=$ characteristic sediment mean size, $\rho_{\mathrm{s}}=$ sediment density, $\sigma_{\mathrm{gd}}=$ standard deviation, $t=$ time, $U_{\mathrm{w}}=$ maximum velocity of water at bed, $U_{\text {mean }}=$ mean flow velocity of the current, $T_{\mathrm{w}}=$ period of oscillation, $v=$ kinematic viscosity, $g=$ acceleration due to gravity, $\alpha_{\mathrm{i}}=$ angle of attack and $B_{\mathrm{d} 0}=$ initial burial depth. Ataie-Ashtiani et al [20] observed that the scour depth depends on pile cap elevations, pile sizes, shapes and presented the following non-dimensional expression of the scour depth at a single uniform submerged complex pier:

$$
\frac{D_{\mathrm{s}}}{D_{\mathrm{p}}}=f\left(\frac{U}{U_{\mathrm{c}}}, \frac{h}{D_{\mathrm{p}}}, \frac{D_{\mathrm{p}}}{D_{\mathrm{pc}}}, \frac{L_{\mathrm{u}}}{L_{\mathrm{f}}}, K_{\mathrm{s}}, K_{\mathrm{sp}}\right),
$$

where $D_{\mathrm{p}}=$ pier width; $U=$ velocity of flow; $U_{\mathrm{c}}=$ threshold flow velocity; $D_{\mathrm{pc}}=$ pier cap width, $L_{\mathrm{u}}$ and $L_{\mathrm{f}}$ are the longitudinal and transverse pier extension; $K_{\mathrm{s}}=$ shape factor of piles; and $K_{\mathrm{sp}}=$ shape factor of pier foundation. Catano-Lopera et al [23] performed experimental investigation on scour and burial mechanics around conical frustums under wave and combined flows conditions on sand bed and proposed the following functional representation for sediment transport phenomenon:

$$
\begin{aligned}
\psi= & f\left(D_{50}, \rho_{\mathrm{s}}, \sigma_{\mathrm{gd}}, \varphi, D, h_{\mathrm{b}}, \varepsilon, B_{\mathrm{do}}, \rho_{\mathrm{b}}, \rho, v, t, T_{\mathrm{w}},\right. \\
& \left.U_{\mathrm{m}}, U, D, W, g\right),
\end{aligned}
$$

where $\psi=$ function representing burial and scour depth; $D_{50}=$ median sand size; $\phi=$ angle of repose; $h_{\mathrm{b}}=$ buried height; $\rho_{\mathrm{b}}=$ buried density; $\rho=$ fluid density; $U_{\mathrm{m}}=$ maximum velocity at bed level; and $W=$ width of flume. Najafzadeh et al [24] numerically studied and predicted scour at vertical piles for regular waves and expressed the scour depth due to regular waves in terms of five nondimensional parameters: pile Reynolds number, grain Reynolds number, sediment number, KC number, and Shields parameter.

$$
D_{\mathrm{s}}=f\left(D_{50}, g, U_{\mathrm{vw}} U_{\mathrm{sv}}, T, v, d, \rho\right)
$$

where $U_{\mathrm{vw}}=$ oscillatory wave velocity; $U_{\mathrm{sv}}=$ maximum shear velocity during wave period; $T=$ wave period.

\subsection{Role of different parameters on equilibrium scour depth}

Dwivedi et al [25] investigated the flow around fish habitat structures in rivers. The backward flow region was reported to move close to the free surface with increase in the submergence ratio. Sumer et al [26] studied scour around vertical pile due to waves and observed that the scour depth decreases with decrease of $\mathrm{KC}$ number. Sumer et al [27] investigated effects of various cross sections on scour around piles due to waves. For all three cases (circular pile with $\mathrm{KC}$ number $=6-7$, square pile with $\mathrm{KC}$ number $=3-4$ for $45^{\circ}$ arrangements, and square pile with $\mathrm{KC}$ number $=10-15$ for $90^{\circ}$ arrangements), scour depth decreases with decrease of $\mathrm{KC}$ number. However, only live bed conditions were studied. Shamloo et al [6] experimentally studied the effect of Froude number on subcritical flow around simple habitat structures. Submergence ratio and Froude number affected the flow pattern around the submerged hemispherical habitat structures, which ultimately influenced the development of scour hole around these structures. Sumer and Fredsøe [28] discussed the effect of cylinder height on scour and observed that scour decreases with the decrease of height of the cylinder. Voropayev et al [7] discussed the influence of $\mathrm{KC}$ number on scour around the short cylinder and observed that scour decreases with decrease of $\mathrm{KC}$ number. Voropayev et al [7] discussed the influence of Shields parameter on scour around short cylinder and concluded that the scour depth decreases with decrease of Shields parameter. Truelsen et al [11] observed that the ratio of scour depth to sphere diameter increases with increase of Shields parameter as represented in figure 3, but the rate of increase is high for small value of Shields parameters. Gradually, the non-dimensional scour depth becomes constant and leads to live bed scour. Figure 3 shows that for small values of Shields parameter, scour depth increases when scour to diameter of sphere ratio vary from 0 to $0.25-0.3$. After that, although scour increases with the ratio, the process leads to live bed scour. In case of live bed scour, the variation of scour to

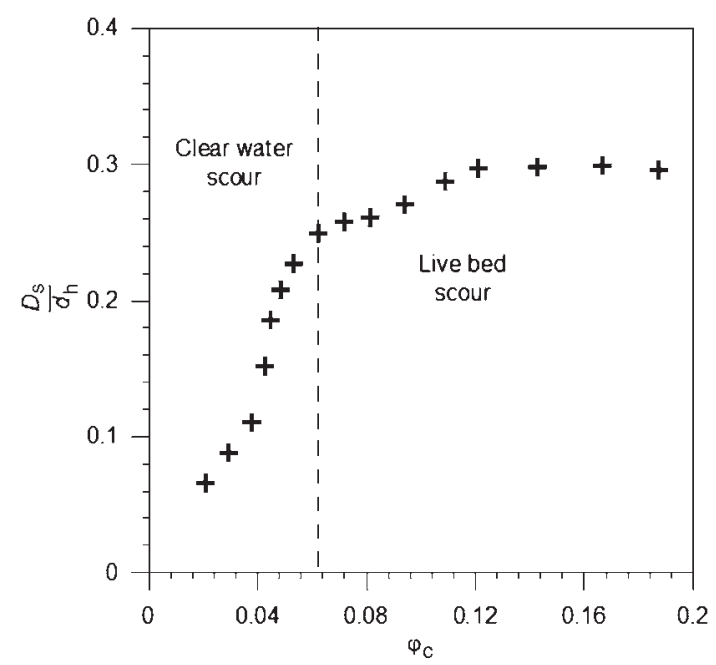

Figure 3. Variation of non-dimensional scour depth versus Shields parameter Truelsen et al [11]. 
diameter of sphere ratio is very small which changes the mode of sediment transport. These changes occur in the upstream and inside of the scour hole, but it does not change the equilibrium scour depth. Dey et al [14] predicted the scour around vertical circular piles due to steady current and waves in clear water and live bed scour condition. It has been reported that the $\mathrm{KC}$ number and vortex shedding are the main responsible factors for scour around the vertical piles. Zhao et al [29] carried out experiments to determine local scour at submerged circular cylinders in steady currents and validated numerically. The effect of Shields parameter on scour were also discussed. The rate of change of scour at equilibrium with respect to height of cylinder decreases with decrease of Shields parameter. Zhao et al [29] also observed that the scour increases with increase of non-dimensional cylinder height as shown in figure 4 . It has also been reported that the maximum equilibrium scour depth occurs for larger height to diameter ratio. Maximum scour depth has been observed to be similar to the results of Roulund et al [30]. The study considered short cylinder. Hence, the vortices at the downstream of the short cylinder could not develop, which also explains the absence of scour at the downstream. For constant velocity, scour depth decreases with decrease in cylinder height. Euler and Herget [31] experimentally analyzed local scour around submerged cylinders based on obstacle Reynolds number and Froude number. The study reported that the equilibrium clearwater scour may be determined with the equivalent length scale of pier diameter and Froude number. The scour depth for non-uniform sediments is estimated, multiplying a factor with the scour depth for case of uniform sediments. Myrhaug and Ong [32] analytically investigated scour at cylindrical pile foundations due to waves and also discussed that shields parameter is useful to determine the two and three-dimensional live bed scour due to random waves.

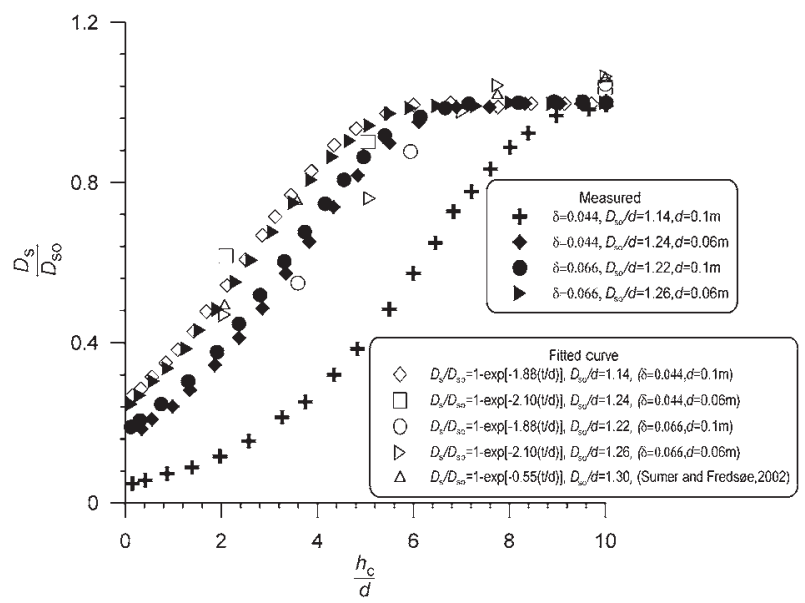

Figure 4. Variation of non-dimensional scour depth with cylinder height, Zhao et al [29].

\subsection{Scour depth around piles of different cross- sections and groups}

Melville and Sutherland [33] experimentally studied the equilibrium scour around bridge piers and observed that the scour is not affected by water depth for depth to diameter ratio more than 4. Sumer et al [27] discussed the effect of the shape of pile on scour process and reported that the effect is moderate. They also found that scour depth is more for square cross-section of pile oriented $45^{\circ}$ with respect to the flow direction and less when orientation is $90^{\circ}$. Figures 5(a) and 5(b) show the temporal variation of scour for square pile. Scour depth is taken as average value of eight locations, four of them at the corner of the piles and other four at the midpoint of the sides of piles. In case of circular piles, scour depth is taken as average value of four locations; upstream, downstream and two side edges of the pile. However, it has also been observed that the scour depth reaches the equilibrium condition at the transitional period. Salim and Jones [34] investigated local scour at submerged complex pile groups and determined the effect of pile spacing on scour depth. It was observed that scour decreases with increase of lateral spacing and increases with the increase of streamwise spacing. Salim and Jones [34] investigated the effect of angle of flow on scour around the submerged complex pile groups. The scour depth decreases with increase of angle of flow. Martinuzzi and AbuOmar [35] experimentally studied the flow around surface mounted pyramids and observed the effect of angle of attack on the flow for square based pyramids. The turbulent flow around pyramids is a function of apex angle, angle of attacks, mean flow, pressure and velocity. At small angle of attack, the periodic vortex shedding is different for slender and broad pyramids. But for, larger angles of attack, periodic vortex shedding influences the wake periodicity around these structures. Sumer et al [36] conducted experiments to evaluate the variation of the scour hole dimensions for various pile spacing. The scour process was observed to be different for single and multiple piles. Interference amongst the individual scour holes were observed with the decrease of pile spacing and the scour hole resembles a single large scour hole. Also, increase of spacing led to the decrease of scour depth. Myrhaug and Ong [37] analytically studied the burial and scour due to waves and currents. The effects of the random waves and currents on the dimensions of scour hole were determined.

\subsection{Bed shear stress}

Bed shear stress induced by the approach flow is pertinent due to its relation with scour and sediment transport. Shamloo et al [6] showed the value of shear stress to be zero at the central plane and negative at the nose of the hemispherical submerged body (figures 6(a-f) and figures $7(a-f)$ ). For different regimes of flow, figures $6(a-f)$ and $7(a-f)$ show the 

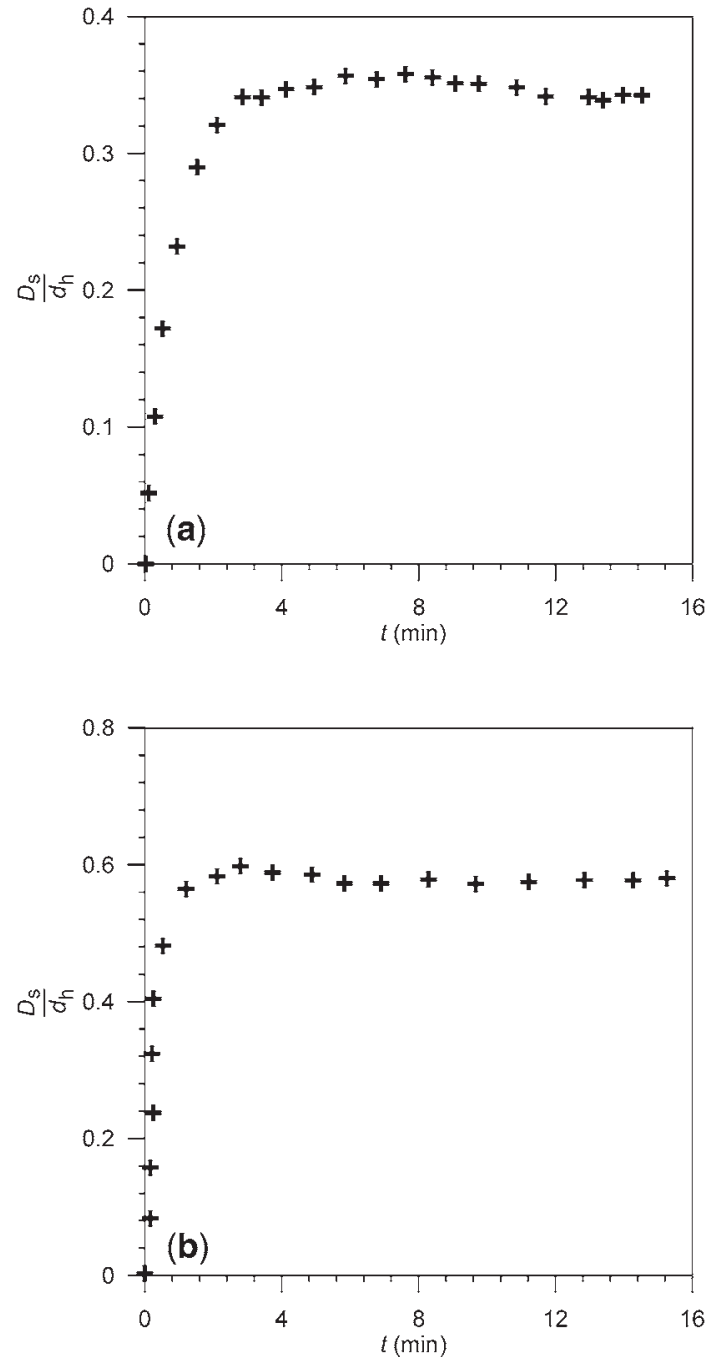

Figure 5. Time development of scour depth for (a) $90^{\circ}$ arrangements and (b) $45^{\circ}$ arrangements, Sumer et al [27].

development of the shear stress in the streamwise and transverse directions for smooth and rough beds. They also computed the region of negative shear stress in the wake and found that erosion starts at the sides of the body. Truelsen [38] studied the flow and scour around spherical bodies due to waves and steady current in the marine environment and estimated the shear stress at the sphere. The shear stress at the sphere decreases compared with circular pile. Dixen et al [39] developed numerical and experimental model around a partially buried sphere in steady current and found the increase of the shear stress. Horseshoe vortices and the streamlines around the partially buried sphere led to the increase of shear stress at the bed.

\subsection{Velocity distributions}

Flow field around partially or fully submerged structures plays an important role in understanding the mechanism and mode of sediment transport around these structures. Formation of the horseshoe vortex at the upstream of these structures plays a major role in the erosion process as shown in figures $8(a, b)$ and $9(a, b)$. Figures $8(a, b)$ show the horseshoe and wake vortices, bow wave, and down flow for partially submerged case, whereas for fully submerged case, figures $9(a, b)$ show the trailing vortices formed at top of cylinder. Castro and Robins [40] experimentally studied the flow characteristics around cubes at various flow conditions and observed the fluctuation of velocity and variation of turbulence and shear in the wake. The separated flow reattached back at the wake of the cube. They also concluded that the reattachment occurs at the wake of the cube when height of cube is larger than the thickness of the boundary-layer. Hunt et al [41] experimentally investigated flows around surface-mounted obstacles using flow visualization techniques and discussed the line of origin of the vortices and separation regions on the downstream side of the obstacles. For three-dimensional obstacles, existence of streamline concentration near the flow separation was not observed. Whereas, for the bluff obstacles, the separated streamline does not get reattached to the surface. Cooker et al [42] numerically and experimentally looked at interaction of wave and submerged semicircular cylinder and discussed the two-dimensional irrotational flows for uniform depth over a semicircular obstacle on flat bed. Martinuzzi and Tropea [43] experimentally studied the two and three-dimensional flows around surface-mounted prismatic obstacles. The flow shows two-dimensional characteristics for obstacles with ratio of width to height greater than six and three-dimensional flow characteristics with the ratio greater than 10. Hussein and Martinuzzi [44] experimentally observed the energy balance for turbulent flow around a cube placed in a channel. The three-dimensional flow at a high Reynolds number around various structures were studied. Voropayev et al [45] experimentally studied the motion of cobbles due to oscillatory flow and found out that oscillatory flow occurs in the coastal water regions due to wave breaking. Kim and Lee [46] studied turbulent flow around obstacles over plane bed in front of the vertical fence. It was observed that relatively smooth flow occurs at the far upstream of the submerged structures in absence of the peak of the streamwise turbulent intensity. Testik et al [47] experimentally investigated the steady and oscillatory flows around fully submerged short cylinder and reported the existence of two types of vortex flow around the structures; horseshoe vortex and lee wake vortex. Demir and García [48] experimentally studied burial of cylinders due to oscillatory flow and presented the oscillating flow characteristics in large water sediment tunnel. They determined the relationship between the Shields parameter and burial depth. Also, correlation between Keulegan-Carpenter and burial depth number was proposed. The burial depth does not depend on the ratio of diameter and density. Manes et al [49] conducted experiments for open channel flow with shallow submergence using particle image 

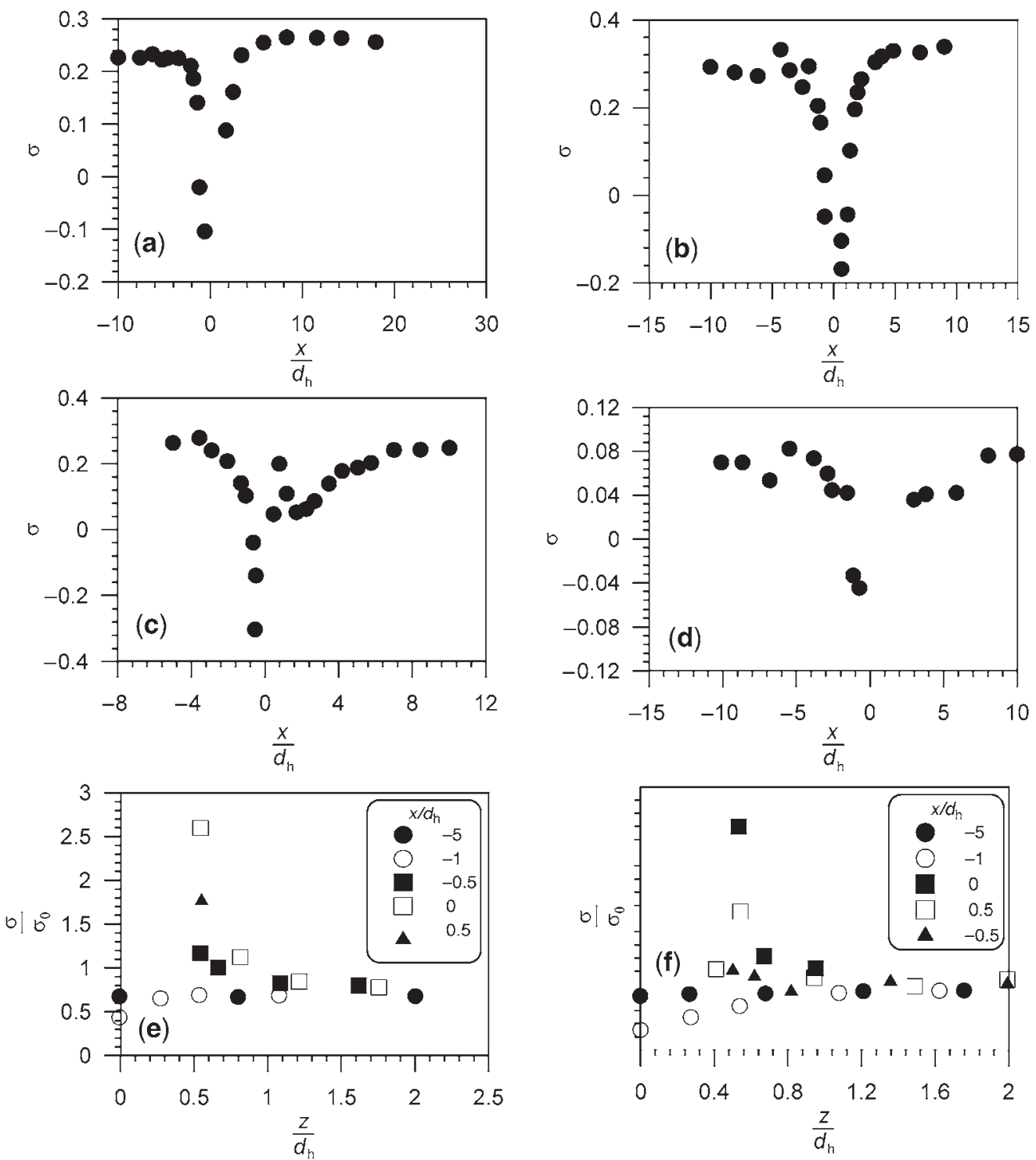

Figure 6. (a-f) Variation of the bed shear stress in the longitudinal and transverse directions for the smooth bed for the different regimes [6].

velocimetry (PIV). They observed that the logarithmic velocity distribution decreases with the increase of depth of flow and flow is not influenced by the bed roughness. Smith and Foster [50] numerically observed flow around a short cylinder on a plane bed. The flow characteristics around two different shape of structures; square and circular cylinder was investigated. The horseshoe vortex varied with time at the upstream side, whereas the arch vortex breaks down at the downstream side. They investigated the flow characteristics for various shapes of obstacles. They also discussed the flow field for wide obstacles having aspect ratio (length/diameter) of five for wide range of Reynolds number. Abad et al [51] numerically investigated the bank erosion pattern of submerged weir along the meandering streams. They measured the three-dimensional velocity distribution around the submerged weir with acoustic
Doppler velocimeter (ADV) and observed good agreement between numerical model results and experimental data. Dey et al [17] discussed flow characteristics around submerged and partially submerged structures. It has been found that the size and intensity of the horseshoe vortices increase with decrease of submergence ratio. On the other hand, horseshoe vortex core is smaller for submerged cylinders than for partially submerged cylinders. However, the size of the core reduces with an increase in submergence ratio, whereas velocity increases with decrease of submergence ratio. The vorticity developed at the top of the cylinder due to trailing vortex and magnitudes of the circulation decreases with increase in submergence ratio. Feeble positive vorticity develops near the dune due to the flow separation and negative vorticity develops above the dune due to the reverse flow in the downstream of the 

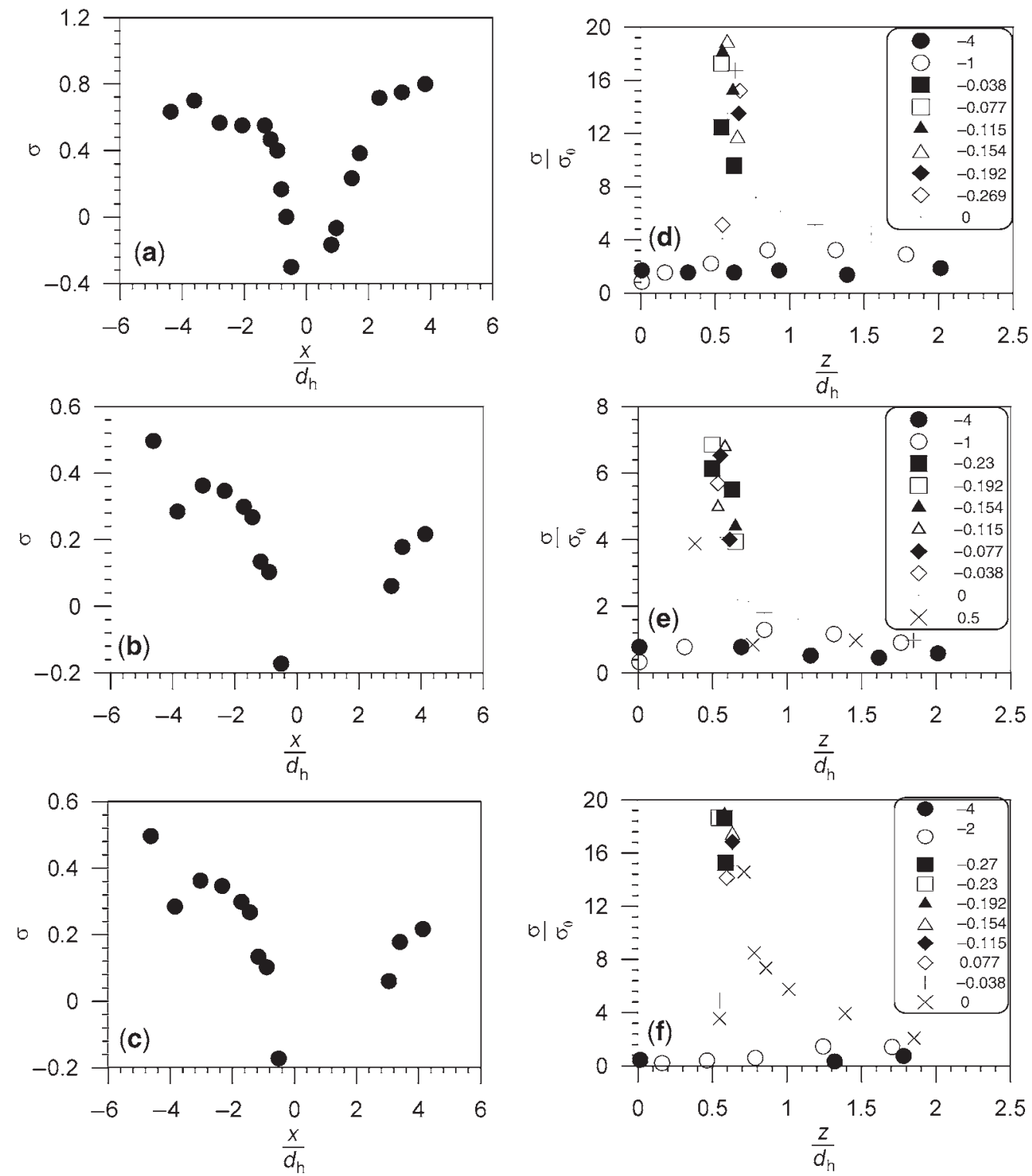

Figure 7. (a-f) Variation of the bed shear stress in the longitudinal and transverse directions for the rough bed for the different regimes [6].

cylinder. Sarkar and Ratha [52] experimentally and numerically studied the flow at submerged cylinders for low submergence and described the velocity distributions around different submerged structures. They measured the velocity distribution of streamwise and vertical velocity components along radial directions from the submerged structure. It has been observed that the non-dimensional time-averaged velocity decreases when the diameter of the cylinder is big compared to when the diameter of the cylinder is small.

\subsection{Flow visualization techniques}

Flow visualization techniques help to visualize the flow of transparent fluids. Kline [53] discussed various methodologies for flow visualization around fully and partially submerged structures. There are several methods of flow visualization: marker methods using dye or smoke, surface powder, neutral density particles, etc.; optical methods using shadow graph, interferometer, etc.; wall trace methods like evaporative and chemical change at wall; bi-refringence and self-visible phenomena like luminous and phase interfaces. Furuya and Miyata [54] experimentally studied the flow visualization of the wake downstream of a roughness element placed on a wall, using dye and hydrogen bubbles. Hunt et al [41] experimentally investigated flows around cuboids and humps using flow visualization techniques. They used an oil film, which is mixture of $10 \%$ zinc oxide powder and $90 \%$ Crisco oil for the visualization and concluded that the technique is useful for highly turbulent flows. However, the rate of 

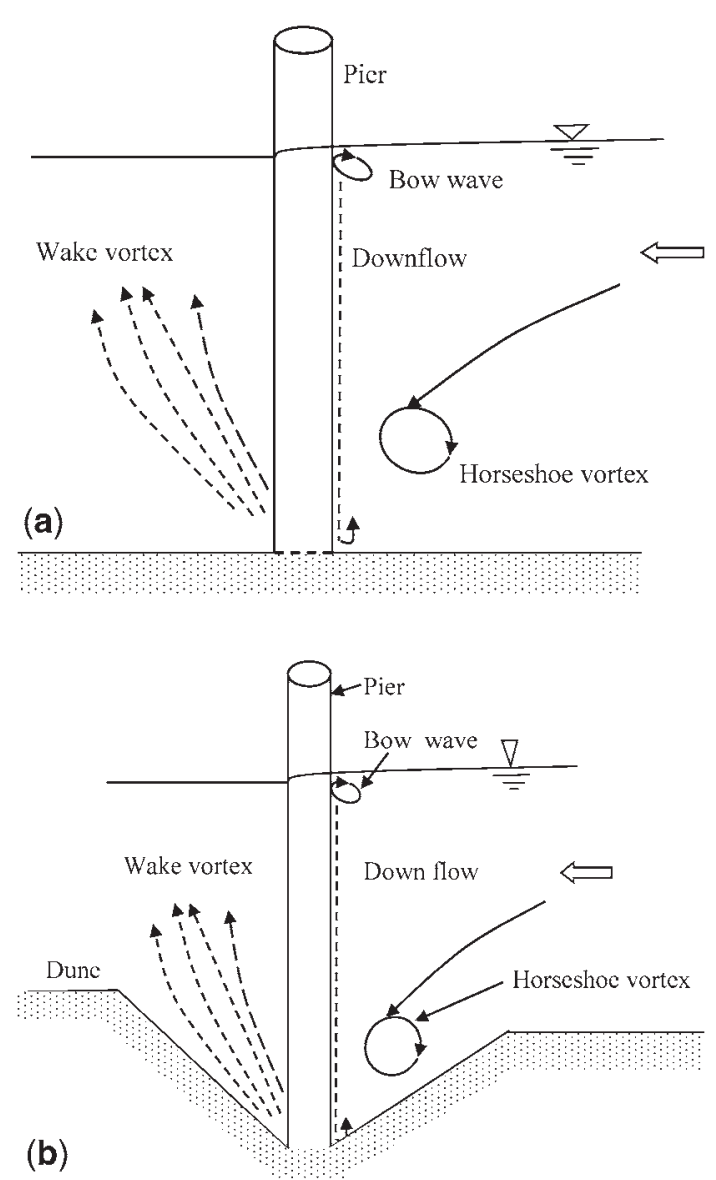

Figure 8. (a) Flow around unsubmerged pier on rigid flat bed [17]. (b) Scour around unsubmerged pier on erodible bed [17].

development of the surface film was very slow. Ziegler [55] experimentally studied the two and three-dimensional flows at prismatic objects in channels of various dimensions using various techniques like laser-sheet visualization techniques and static pressure measurements. Dimaczek et al [56] used flow visualization technique to study flows around objects at high Reynolds numbers. Martinuzzi and Tropea [43] also experimentally studied the two and threedimensional flows at prismatic objects in channels of various dimensions and used various techniques like lasersheet visualization techniques and static pressure measurements. Chou and Chao [57] investigated shedding of horseshoe vortices from rectangular cylinders. They applied two types of flow visualization technique; one is dye streaks at the upstream of the test section while another one is surface dye sheet for the downstream of the cylinder. They observed that the horseshoe vortices evolve into wavy structure at the downstream of the cylinders. Sadeque et al [18] applied the flow visualization techniques to estimate the shear stress and flow characteristics around the cylinders. The generated horseshoe vortex remain closer to the structure for the fully submerged cylinder in comparison with the partially submerged cylinder.

\subsection{Scour depth estimation formulas}

Sumer et al [27] developed expression for time variation equilibrium scour at transitional period, which is given below:

$$
D_{\mathrm{S}}=D_{\mathrm{S} 0}\left(1-\exp -\frac{-t}{T_{\mathrm{s}}}\right)
$$

where $D_{\mathrm{S} 0}=$ equilibrium scour depth; $T_{\mathrm{s}}=$ time scale that can be calculated from the information of scour depth versus time by calculating the slope of the tangent to the $S(t)$ curve at $t=0$. Sumer and Fredsøe [28] developed the equation for calculating the scour depth near the submerged vertical cylinder, which is given below

$$
\frac{D_{\mathrm{S}}}{D_{\mathrm{S} \alpha}}=1-\exp \left(-A \frac{h_{\mathrm{c}}}{d_{\mathrm{c}}}\right)
$$

where $D_{\mathrm{S} \alpha}=$ scour depth for a pile with infinite height; $A=0.55$ is a fitted coefficient; $h_{\mathrm{c}}=$ height of the cylinder and $d_{\mathrm{c}}=$ diameter of the cylinder.

Myrhaug et al [58] analytically studied scour at spherical bodies and burial due to waves. It was observed that the formula to express scour due to waves may also be applied for estimating scour depth due to random waves. Following equations are proposed to calculate the scour and self-burial depth:

$$
\frac{D_{\mathrm{s}}}{d}=0.3\{1-\exp [-0.3 \ln (K C)]\} \quad \text { for } \quad K C \geq 1
$$

and

$$
\frac{e}{d}=0.5\{1-\exp [-q(K C-r)]\} \quad \text { for } \quad K C \geq r,
$$

where $e=$ self-burial depth; $q$ and $r$ are constants, the values of which are 0.08 and 1.4 respectively. Amini et al [59] experimentally studied local scour around pile groups on uniform bed material in shallow-water flow and measured the scour depth at vertical pile groups for steady flows. They observed that the scour depth depends on diameter of pile, spacing and submergence ratio. The following equations were proposed for computing the scour depth $\left(D_{\mathrm{s}}\right)$ at pile groups:

$$
\begin{gathered}
K_{\mathrm{phf}}=S_{\mathrm{rs}}^{3}-2.4 S_{\mathrm{rs}}^{2}+2.4 S_{\mathrm{rs}} \text { for } R^{2}=0.95, \\
K_{\mathrm{phf}}=1.7 S_{\mathrm{rs}}^{3}-4 S_{\mathrm{rs}}^{2}+3.3 S_{\mathrm{rs}} \text { for } R^{2}=0.97 \\
K_{\mathrm{cps}}=C m^{0.05} n^{-0.44}\left(\frac{S}{d}\right)^{-0.38} \\
D_{\mathrm{s}}=K_{\mathrm{phf}} K_{\mathrm{cps}} y_{\mathrm{s}}
\end{gathered}
$$

where $K_{\mathrm{phf}}=$ pile group height adjustment factor, which depends on correlation coefficient $\left(R^{2}\right) ; S_{\mathrm{rs}}=$ submergence ratio; $K_{\mathrm{cps}}=$ correction factor for pile spacing; 

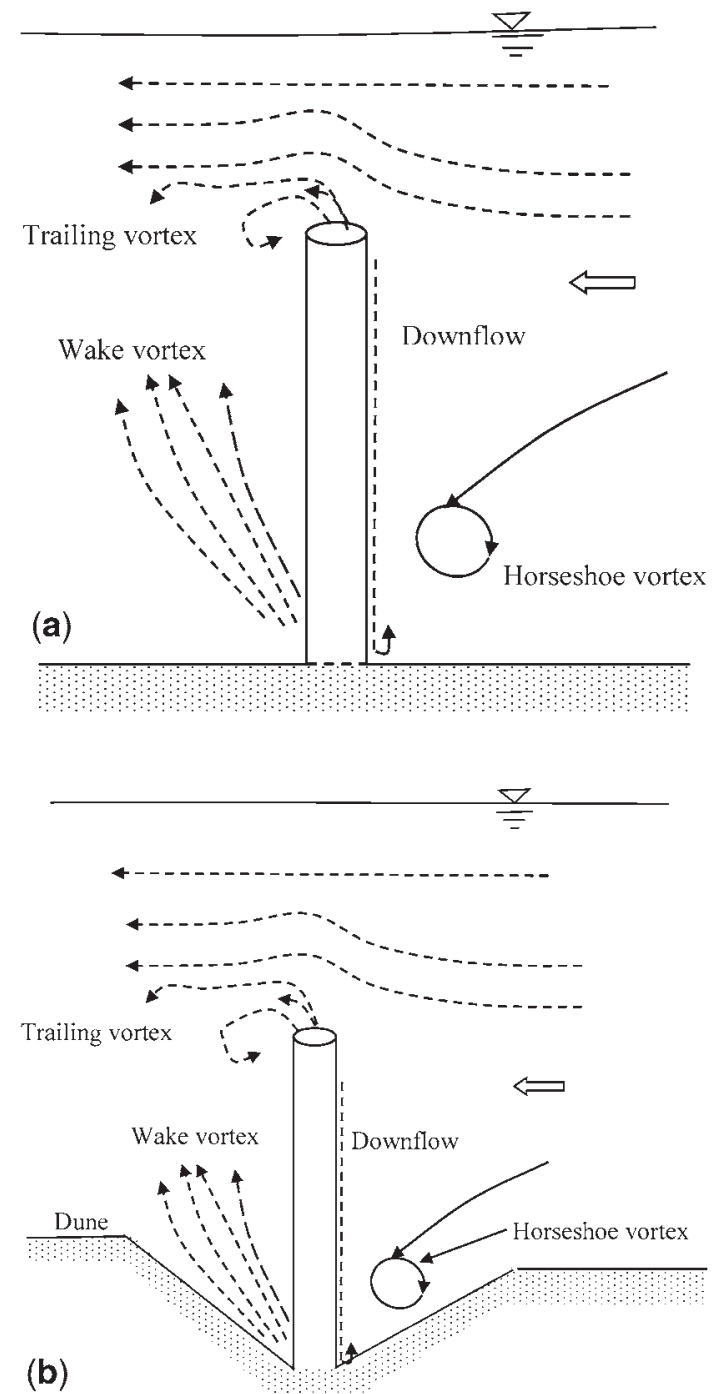

Figure 9. (a) Scour around submerged pier on rigid flat bed (b) on erodible bed, Dey et al [17].

$C=$ constant; $m$ and $n=$ number of rows and columns in the group respectively; $S=$ pile spacing; $y_{\mathrm{s}}=$ scour depth at equilibrium for partially submerged cylindrical pier.

\subsection{Time variation of scour depth}

Time variation of scour depth is important to predict the evolution of the scour hole as well as the deposition pattern around the submerged structures. Melville and Raudkivi [60] conducted experiment on local scour around compound pier, measured and plotted the variation of scour depth versus height of pile cap. It has been noticed that the initial scour develops behind the compound pier due to wake vortex and after that it gradually reaches around the compound pier. Briaud et al [61] plotted multiple hydrographs of the temporal variation of scour depth for piers in deep water and found that the pier length is important parameter influencing the scour depth. Truelsen et al [11] studied time scale of the scour process and expressed it as a function of the Shields parameter in case of steady current and Shields parameter and $\mathrm{KC}$ number in the case of waves. They showed that the variation of non-dimensional time scale of scour process versus Shields parameter and KC number and showed that the scour depth increase with increase of Shields parameter and KC number. They also showed that the time scale for the self-burial process is dependent on Shields parameter and KC number. AtaieAshtiani et al [20] also conducted experimental investigation on local scour around compound pier, measured and plotted the variation of scour depth versus height of pile cap as shown in figure 10. The pile cap extensions on either side of the complex pier, when at the bed level, protect the mobile bed from scour. For pile cap extension at the bed level, initiation of scour as well as the equilibrium condition takes relatively longer time in comparison to different height of the cap to the bed level. For pile cap at the bed level, it has also been noticed that the initial scour develops behind the compound pier and subsequently it reaches around the compound pier. However, the scour zone does not cover the pier completely; rather sediment is transported from the upstream of the pier and deposited at the downstream. Zhao et al [29] observed that the time taken for the scour process to achieve equilibrium was much smaller for smaller values of the Shields parameter (figure 11). It can be seen that the scour depth reaches equilibrium condition for all the experiments. Zhao et al [29] also observed the evolution and characteristics of scour bed profiles at the upstream and downstream of the submerged structures and reported the differences in the bed profiles based on the Shields parameter. For smaller values of Shields parameter, small ripples are formed at the upstream and ridge shaped sand dune formed at the downstream wake of the submerged structure. Whereas, considerably larger ripples formed at the upstream of the structure for higher values of Shields parameter and also the dunes at the downstream moved further with the wakes of the structure. Kim et al [62] numerically investigated the clear water scour around cylinders for various configurations. They discussed the development of scour at different time intervals. In case of side by side configuration, initially, scour occurs around the side of the cylinders. Gradually, scour upstream of cylinder emerges due to the effect of horseshoe vortices close to the bed. Later on, scour hole of cylinders join together, which increases in size before it reaches the equilibrium dimension. For tandem cylinder arrangement, initially the scour characteristics remain same but later, with the progress of time, scour starts at the nose and sides with deposition at the downstream of the cylinder.

\subsection{Scour protection}

Quinn [15] applied combination of various processes in the column of water from surface to bottom to protect scour in 


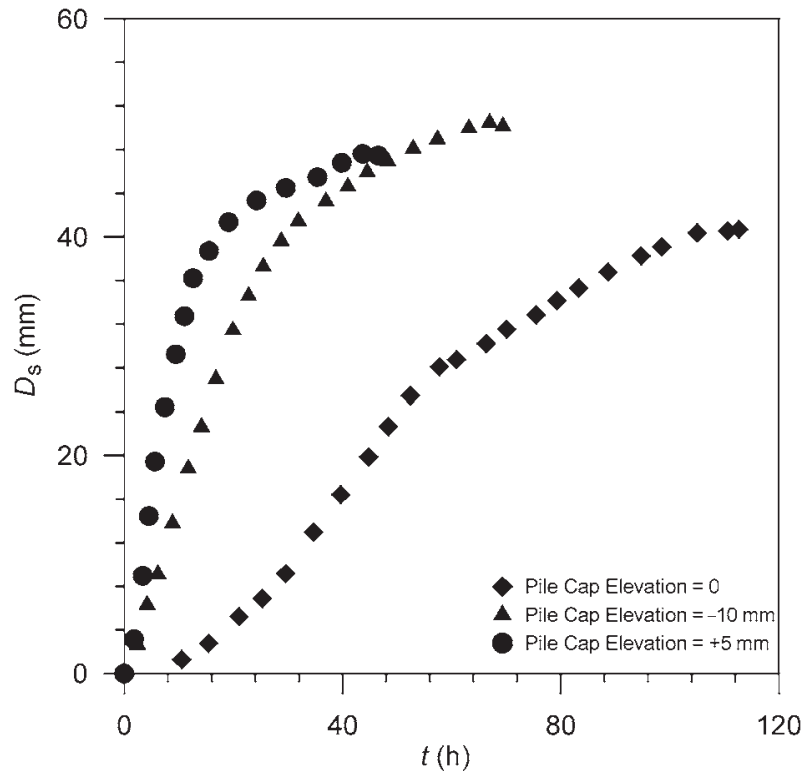

Figure 10. Temporal development of scour depth for various pile cap elevation, Ataie-Ashtiani et al [20].

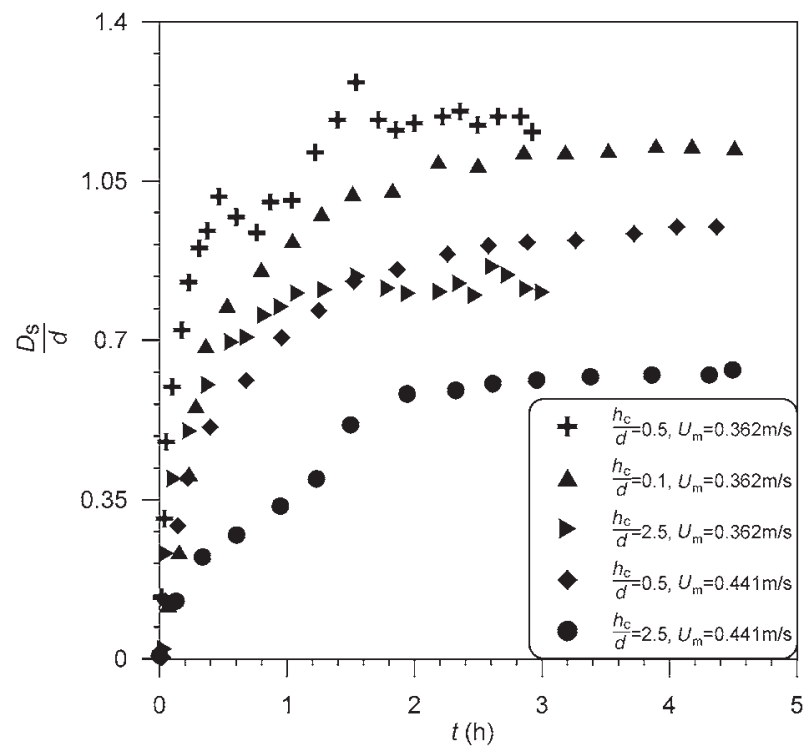

Figure 11. Time history of scour depth at the most updtream point of the cylinder surface [29].

the shipwreck site with the constant interaction of different materials and energy across the boundaries. Ataie-Ashtiani et al [20] experimentally studied the scour protection around compound pier with addition of pile cap. With increase of pile cap height, scour depth was observed to increase or decrease depending on the width of the complex pier. Scour depth increases, when pile cap position is above the bed level, and it decreases, when the pile cap position is at the bed level. Ataie-Ashtiani et al [20] obtained that the equilibrium scour depth decreases if the scour hole touches the top of the pile cap. The pile cap creates an obstruction for the downflow and the horseshoe vortex to reach bed level. For the case of undermining of the pile cap due to excessive scour, the flow penetrates further down and the scour depth increases further below the pile cap.

\section{Other aspects of scour around vertical submerged structures}

Olsen and Melaaen [63] applied the unsteady NavierStokes equation to study scour around obstacles, whereas steady Navier-Stokes equation has been applied by Olsen and Kjellesvig [64]. Baglio et al [65] experimentally studied the measurement of the three-dimensional scour processes due to wave around vertical cylindrical pile on sand bed using a stereo vision approach and compared equilibrium scour depth with the relation of Sumer et al [26]. It has been validated with Sumer et al [26]. Li and Zhu [66] applied three-dimensional $k-\varepsilon$ model to simulate the free surface above a submerged structure. The model results of the variation of the free surface and the velocities are validated using numerical simulations of the passage of a wave over a submerged cube. Sousa [67] conducted experiments on flow around objects using two-dimensional digital particle image velocimetry. Correlation between kinetic energy and vortices in the flow were established. The swirling strength and normalized angular momentum of large scale vortical structures were also identified. Coleman [68] conducted experiments on scour at complex pile groups. Various bed levels were considered during the experiments. Considering linear variation in scour depth, a methodology was developed with the existing equations to calculate scour depth around complex piers. Liu et al (2008) experimentally and numerically studied the effect of the turbulence modelling on sediment transportation along with the effect of turbulent eddy viscosity term and observed good matching with experiments. Zhao et al [69] experimentally studied local scour around subsea caissons in steady currents. Experiments show that the horseshoe vortex is dominant in comparison to increase in velocity at the corners of the caisson. Ong et al [70] analytically estimated the equilibrium scour depth due to two and threedimensional waves plus current around vertical piles using stochastic method and the empirical formulas of Sumer and Fredsøe [71]. It has been found that equilibrium scour depth for linear waves is larger than for nonlinear waves.

\section{Limitations}

Research works have been conducted to predict the local scour and flow characteristics around different submerged structures for various flow conditions. Most of the previous studies that have been carried out have limitations so far as 
the KC number, orientation of the submerged structures to the flow, aspect ratio, surface tension, Reynolds number, cross-sectional area, specific gravity, sediment size, submergence ratio, flow conditions, etc. are concerned. Even the studies were limited to the determination of scour depth around regular shapes of submerged structures. Moreover, most of the reported studies have been conducted over cohesionless sediment beds and temporal evolution of the scoured bed around these structures of various cross sections has not been modeled. Further, methodology of predicting various parameter values for the prototype from the results acquired from the model experiments have not been proposed.

\section{Achievements}

Various investigations have been carried out on the hydraulics and local scour around submerged structures. Different empirical relations are established to express the scour depth in terms of structure diameter, KC number, sediment size, Reynolds number, submergence ratio, flow conditions, etc. Scour depth around submerged cylinders under clear water and live bed conditions have been determined and compared with partially submerged cylinder scour depth. The equilibrium scour depth has been investigated around the submerged cylinder under clear water scour condition in coarse uniform sand. However, more of such studies are encouraged to understand the flow physics around the submerged structures and the interaction mechanism of the flow along with the sediment particles.

\section{Future scope of research}

Various studies have been carried out on flow and scour around different vertical submerged structures and experiments, numerical and analytical studies have been conducted for better understanding the problem. Yet, there is definite dearth of information regarding different aspects of flow and erosion around these structures and it remains unexplored in many cases. Different investigators have urged the need to study scour around practical shapes of fish habitat structures. Also, doubts were raised about the two or three-dimensional nature of the flow close to the submerged structures. Studies need to be conducted to generalize the expression representing the scour depth around single and group of submerged structures for wide variations in various parameters like $\mathrm{KC}$ number, orientation of the submerged structures, aspect ratio, Reynolds number, cross-sectional area, sediment size, submergence ratio, flow conditions, live bed conditions, etc. Further, research works are needed to explore erosion around these submerged structures for live bed conditions, unsteady flow and cohesive sediments. In this context, it is also pertinent to mention that no attempt has been made to upscale the laboratory results and predict the same for the prototype. Hence, more laboratory investigations and large-scale model studies are required to understand the problem of scour around various submerged structures. Moreover, theoretical or numerical approach may be developed for the validation of the experimental and field measurements for wide range of flow conditions.

\section{Notation}

The following symbols and their meanings are used in this paper:

A

0.55 is a fitted coefficient

$B_{d 0} \quad$ initial burial depth

C constant

$D \quad$ flow depth or water depth

$D_{\mathrm{m}} \quad$ characteristic sediment mean size

$D_{\mathrm{p}} \quad$ pile width

$D_{\text {pc }} \quad$ pier cap width

$D_{\mathrm{s}} \quad$ maximum scour at any time $t$

$D_{S \alpha} \quad$ scour depth for a pile with infinite height

$D_{S 0} \quad$ equilibrium scour depth

$D_{50} \quad$ median sand size

$d \quad$ diameter of pile

$d_{c} \quad$ diameter of the cylinder

$d_{\mathrm{h}} \quad$ diameter of hemispherical obstacle

e self-burial depth

$g \quad$ acceleration due to gravity

$H_{\mathrm{i}} \quad$ wave height

$h$ pier height

$h_{\mathrm{b}} \quad$ buried height

$h_{c} \quad$ height of the cylinder

$K C \quad$ Keulegan-Carpenter number

$K_{\text {cps }} \quad$ correction factor for pile spacing

$K_{\mathrm{phf}} \quad$ pile group height adjustment factor

$K_{\mathrm{s}} \quad$ shape factor of piles

$K_{\text {sp }} \quad$ shape factor of pier foundation

$L \quad$ wave length

$L_{\mathrm{c}} \quad$ length of the cylinder

$L_{\mathrm{f}} \quad$ transverse pier extension

$L_{\mathrm{t}} \quad$ length of parallel wall

$L_{\mathrm{u}} \quad$ longitudinal pier extension

$m$ number of rows in the group

$\mathrm{N}_{\mathrm{s}} \quad$ sediment number

$N \quad$ number of column in the group

$q, r \quad$ constants

$R_{\mathrm{e}} \quad$ Reynolds number

$S \quad$ pile spacing

$S(\mathrm{t}) \quad$ scour depth at time $t=0$

$S_{\mathrm{rs}} \quad$ submergence ratio

$T \quad$ wave period

$T_{\mathrm{s}} \quad$ time scale 
$T_{\mathrm{w}} \quad$ period of oscillation

$t$ time

$U \quad$ velocity of flow

$U_{\mathrm{c}} \quad$ threshold flow velocity

$U_{\mathrm{m}} \quad$ velocity at bed level

$U_{\text {mean }}$ mean flow velocity of the current

$U_{\text {sv }} \quad$ maximum shear velocity during wave period

$U_{\mathrm{w}} \quad$ maximum velocity of water at bed

$U_{\mathrm{vw}} \quad$ oscillatory wave velocity

$W \quad$ width of flume

$x \quad$ longitudinal distance measured from the center of the obstacle

$y_{\mathrm{s}} \quad$ scour depth at equilibrium for unsubmerged cylindrical pier

$z \quad$ transverse distance from the center plane of the flume and the body

$\alpha \quad$ skew angle of pile group

$\alpha_{i} \quad$ angle of attack

$\varepsilon \quad$ surface roughness of cylinder

$\theta \quad$ angle between parallel and perpendicular wall

$v \quad$ kinematic viscosity

$\rho \quad$ fluid density

$\rho_{b} \quad$ buried density

$\rho_{c} \quad$ density of cylinder

$\rho_{\mathrm{s}} \quad$ sediment density

$\sigma_{0} \quad$ bed shear stress in the approaching flow

$\sigma_{\mathrm{gd}} \quad$ standard deviation

$\tau_{\mathrm{vn}} \quad$ transverse bed shear stress

$\tau_{\mathrm{vs}} \quad$ streamwise bed shear stress

$\varphi_{\mathrm{c}} \quad$ shields parameter

$\psi \quad$ burial depth and scour depth

$\phi \quad$ angle of repose

\section{References}

[1] Hannah C R 1978 Scour at pile groups. Research Report 28-3, Civil Engineering Department University of Canterbury, Christchurch, New Zealand

[2] Albers C D 1997 Hydraulics of a three obstacle cluster in open channels. MSc thesis, University of Alberta, Edmonton, Alta, Canada

[3] Tang C J and Chang J H 1998 Flow separation during solitary wave passing over submerged obstacle. J. Hydraul. Eng. 124(7): 742-749

[4] Voropayev S I, Mc Eachern G B, Boyer D L and Fernando H J S 1999 Dynamics of sand ripples and burial/scouring of cobbles in oscillatory flow. Appl. Ocean Res. 21(5): 249-261

[5] McNinch J E, Wells J T and Drake TG 2001 The fate of artifacts in an energetic, shallow-water environment: scour and burial at the wreck site of Queen Anne's Revenge. South-eastern Geol. 40(1): 19-27

[6] Shamloo H, Rajaratnam N and Katopodis C 2001 Hydraulics of simple habitat structures Hydrauliquede's structures d'habitat simples. J. Hydraul. Res. 39(4): 351-366
[7] Voropayev S I, Testik F Y, Fernando H J S and Boyer D L 2003 Burial and scour around short cylinder under progressive shoaling waves. Ocean Eng. 30(13): 1647-1667

[8] Myrhaug D and Rue H 2003 Scour below pipelines and around vertical piles in random waves. Coast. Eng. 48(4): 227-242

[9] Myrhaug D and Rue H 2005 Scour around groups of slender vertical piles in random waves. Appl. Ocean Res. 27(1): $56-63$

[10] Sumer B M, Fredsøe J 1998 Wave scour around group of vertical piles. ASCE J. Waterway Port Coast. Ocean Eng. 124(5): 248-55

[11] Truelsen C, Sumer B M and Fredsøe J 2005 Scour around spherical bodies and self burial. ASCE J. Waterway Port Coast.Ocean Eng. 131(1): 1-13

[12] Catano-Lopera A Y and Garcia M H 2005 Burial of short cylinders induced by scour and bedforms under waves plus currents. Proceedings of world water and environmental resources congress conference ASCE, Alaska, 14-19 May

[13] Catano-Lopera A Y and Garcia M H 2006 Burial of short cylinders induced by sandwaves and scour under combined waves and currents. J. Waterway Port. Coast. Ocean Eng. 132: 439-449

[14] Dey S, Sumer B M and Fredsøe J 2006 Control of scour at vertical circular piles under waves and current. J. Hydraul. Eng. 132(3): 270-279

[15] Quinn S 2006 The role of scour in shipwreck site formation processes and the preservation of wreck-associated scour signatures in the sedimentary record evidence from seabed and sub-surface data. J. Arch. Sc. 33(10): 1419-1432

[16] Hatton K A, Foster D A, Traykovski P and Smith H D 2007 Numerical simulations of the flow and sediment transport regimes surrounding a short cylinder. IEEE J. Ocean Eng. 32(1): 249-259

[17] Dey S, Raikar R V and Roy A 2008 Scour at submerged cylindrical obstacles under steady flow. J. Hydraul. Eng. 134(1): 105-109

[18] Sadeque M A F, Rajaratnam N and Loewen M R 2008 Flow around cylinders in open channels. Eng. Mech. ASCE 134(1): 60-71

[19] Myrhaug D, Ong M C, Føien H, Gjengedal C and Leira B J 2009 Scour below pipelines and around vertical piles due to second-order random waves plus a current. Ocean Eng. 36(8): 605-616

[20] Ataie-Ashtiani B, Baratian-Ghorghi Z and Beheshti A A 2010 Experimental investigation of clear-water local scour of compound piers. J. Hydraul. Eng. 136(6): 343-351

[21] Euler E and Herget J 2012 Controls on local scour and deposition induced by obstacles in fluvial environments. Catena 91: 35-46

[22] Catano-Lopera A Y and Garcia M H 2007 Geometry of scour hole around and the influence of the angle of attack on the burial of finite cylinders under combined flows. Ocean Eng. 34(5-6): 856-869

[23] Catano-Lopera A Y, Landry J B and Garcia H M 2011 Scour and burial mechanics of conical frustums on a sandy bed under combined flow conditions. Ocean Eng. 38(10): $1256-1268$

[24] Najafzadeh M, Barani G A and Hessami-Kermani M R 2013 Group method of data handling to predict scour depth around 
vertical piles under regular waves. Scientia Iranica A 20(3): 406-413

[25] Dwivedi V K, Rajaratnam N and Katopodis C 1992 An exploratory study of fish habitat structures in rivers. Proceedings of eleventh Canadian Hydrotechnical Conference 26(1): 573-581

[26] Sumer B M, Fredsøe J and Christiansen N 1992 Scour around vertical pile in waves. J. Waterway Port Coast. Ocean Eng. 117(1): 15-31

[27] Sumer B M, Christiansen N and Fredsøe J 1993 Influence of cross-section on wave scour around piles. J. Waterway Port Coast. Ocean Eng. 119(5): 477-495

[28] Sumer B M and Fredsøe J 2002 The mechanics of scour in the marine environment. World Scientific, Singapore

[29] Zhao M., Cheng L and Zang Z 2010 Experimental and numerical investigation of local scour around a submerged vertical circular cylinder in steady currents. Coast. Eng. 57(8): 709-721

[30] Roulund A, Sumer B M, Fredsøe J and Michelsen J 2005 Numerical and experimental investigation of flow and scour around a circular pile. J. Fluid Mech. 534: 351-401.

[31] Euler T and Herget J 2011 Obstacle-Reynolds-number based analysis of local scour at submerged cylinders. J. Hydraul. Eng. 49(2): 267-271

[32] Myrhaug D and Ong M C 2013 Scour around vertical pile foundations for offshore wind turbines due to long-crested and short-crested nonlinear random waves. J. Offshore Mech. Arctic Eng. 135(1): 011103-6

[33] Melville B M and Sutherland A J 1988 Design method for local scour at bridge piers. J. Hydraul. Eng. 114(10): $1210-1226$

[34] Salim M and Jones J S 1996 Scour around exposed pile foundations. Compilation of Conference Scour Papers (1991-1998), ASCE, Reston, VA

[35] Martinuzzi R J and AbuOmar M 2003 Study of the flow around surface mounted pyramids. Exp. fluids 34(3): 379-389

[36] Sumer B M, Fredsøe J, Lamberti A, Zanuttigh B, Dixen M, Gislason K and Di Penta A F 2005 Local scour at roundhead and along the trunk of low crested structures. Coast. Eng. 52(10-11): 995-1025

[37] Myrhaug D and Ong M C 2009 Burial and scour of short cylinders under combined random waves and currents including effects of second order wave asymmetry. Coast. Eng. 56(1): 73-81

[38] Truelsen C 2002 Flow and scour around spherical bodies. $\mathrm{PhD}$ thesis, Technical University of Denmark, Lyngby, Denmark

[39] Dixen M, Sumer B M and Fredsøe J 2013 Numerical and experimental investigation of flow and scour around a halfburied sphere. Coast. Eng. 73: 84-105

[40] Castro I P and Robins A G 1977 The flow around a surfacemounted cube in uniform and turbulent streams. J. Fluid Mech. 79(2): 307-335

[41] Hunt J C R, Abell C J, Peterka J A and Woo H 1978 Kinematical studies of the flows around free or surfacemounted obstacles; applying topology to flow visualization. J. Fluid Mech. 86(1): 179-200

[42] Cooker M J, Peregrine D H, Vidal C and Dold J W 1990 The interaction between a solitary wave and a submerged semicircular cylinder. J. Fluid Mech. 215: 1-22
[43] Martinuzzi R and Tropea C 1993 The flow around surface mounted, prismatic obstacles placed in a fully developed channel flow. J. Fluids Eng. 115(1): 85-92

[44] Hussein H J and Martinuzzi R J 1996 Energy balance for turbulent flow around a surface mounted cube placed in a channel. Phys. Fluids 8(3): 764-780

[45] Voropayev S I, Roney J, Boyer D L, Fernando H J S and Houston W N 1998 The motion of large bottom particles (cobbles) in a wave-induced oscillatory flow. Coast. Eng. 34(3-4): 197-219

[46] Kim H B and Lee S J 2001 Time-resolved velocity field measurements of separated flow in front of a vertical fence. Exp. Fluids 31(3): 249-257

[47] Testik F Y, Voropayev S I and Fernando H J S 2005 Flow around a short horizontal bottom cylinder under steady and oscillatory flows. Phys. Fluids 17(4):047103-12

[48] Demir S T and García M H 2007 Experimental studies on burial of finite-length cylinders under oscillatory flow. $J$. Waterway Port Coast. Ocean Eng. 133(2): 117-124

[49] Manes C, Pokrajac D and McEwan I 2007 Double averaged open channel flows with small relative submergence. $J$. Hydraul. Eng. 133(8): 896-904

[50] Smith H D and Foster D L 2007 The three-dimensional flow around a bottom-mounted short cylinder. J. Hydraul. Eng. ASCE 133(5): 534-544

[51] Abad J D, Rhoads B L, Guneralp I and Garcia M H 2008 Flow structure at different stages in a meander bend with bendway weirs. J. Hydraul. Eng. 134(8): 1052-1063

[52] Sarkar A and Ratha D 2014 Flow around submerged structures subjected to shallow submergence over plane bed. $J$. Fluids Struct. 44: 166-181

[53] Kline S J 1969 Flow visualization Report 21607, National Committee for Fluid Mechanics Films, Stanford University

[54] Furuya Y and Miyata M 1972 Visual studies on the wake of a roughness element proximate to a wall. Memo. Fac. Eng. Nagoya Univ. 24(1): 278-293

[55] Ziegler T 1987 Experimentelle untersuchungen der stromung iiber ein zweidimensionales Hindernis, Diplomarbeit at the Lehrstuhl fur Stromungsmechanik of the University Erlangen-Nuremberg

[56] Dimaczek G, Kessler R, Martinuzzi R and Tropea C 1989 The flow over two-dimensional surface-mounted obstacles at high Reynolds numbers. Proceedings of seventh symposium on turbulent shear flows, Standford, CA

[57] Chou J H and Chao S Y 2000 Branching of a horseshoe vortex around surface-mounted rectangular cylinders. Exp. Fluid. 28(5): 394-402

[58] Myrhaug D, Føien H and Rue H 2007 Tentative engineering approach to scour around spherical bodies in random waves. Appl. Ocean Res. 29(1-2): 80-85

[59] Amini A, Bruce W, Melville M, Ali T M and Ghazali A H 2012 Clear-water local scour around pile groups in shallowwater flow. J. Hydraul. Eng. ASCE, 138(2): 177-185

[60] Melville B W and Raudkivi A J 1996 Effects of foundation geometry on bridge pier scour. J. Hydraul. Eng. 122(4): 203-209

[61] Briaud J L, Chen H C, Li Y and Nurtjahyo P 2004 SRICOSEFA method for complex piers in fine-grained soils. $J$. Geotech. Geoenviron. Eng. 130(11): 1180-1191

[62] Kim H S, Nabi M, Kimura I and Shimizu Y 2014 Numerical investigation of local scour at two adjacent cylinders. Adv. Water. Resour. 70: 131-147 
[63] Olsen N R B and Melaaen M C 1993 Three-dimensional calculation of scour around cylinders. J. Hydraul. Eng. 119(9): 1048-1054

[64] Olsen N R B and Kjellesvig H M 1998 Three-dimensional numerical flow modelling for estimation of maximum local scour. J. Hydraul. Eng. 36(6): 579-590

[65] Baglio S, Faraci C, Foti E and Musumeci R 2001 Measurements of the 3-D scour process around a pile in an oscillating flow through a stereo vision approach. Measurement 30(2): $145-160$

[66] Li C W and Zhu B 2002 A sigma coordinate 3D k- $\varepsilon$ model for turbulent free surface flow over a submerged structure. Appl. Math. Model. 26(12): 1139-1150
[67] Sousa J M M 2002 Turbulent flow around a surface-mounted obstacle using 2D-3C DPIV. Exp. Fluids 33(6): 854-862

[68] Coleman S E 2005 Clearwater local scour at complex piers. J. Hydraul. Eng. 131(4): 330-334

[69] Zhao M, Zhu X, Cheng L and Teng B 2012 Experimental study of local scour around subsea caissons in steady currents. Coast. Eng. 60: 30-40

[70] Ong M C, Myrhaug D and Hesten P 2013 Scour around vertical piles due to long-crested and short-crested nonlinear random waves plus a current. Coast. Eng. 73: 106-114

[71] Sumer B M and Fredsøe J 2001 Scour around pile in combined waves and current. J. Hydraul. Eng. 127(5): 403-411 